LA-UR-01-3211

Approved for public release; distribution is unlimited.

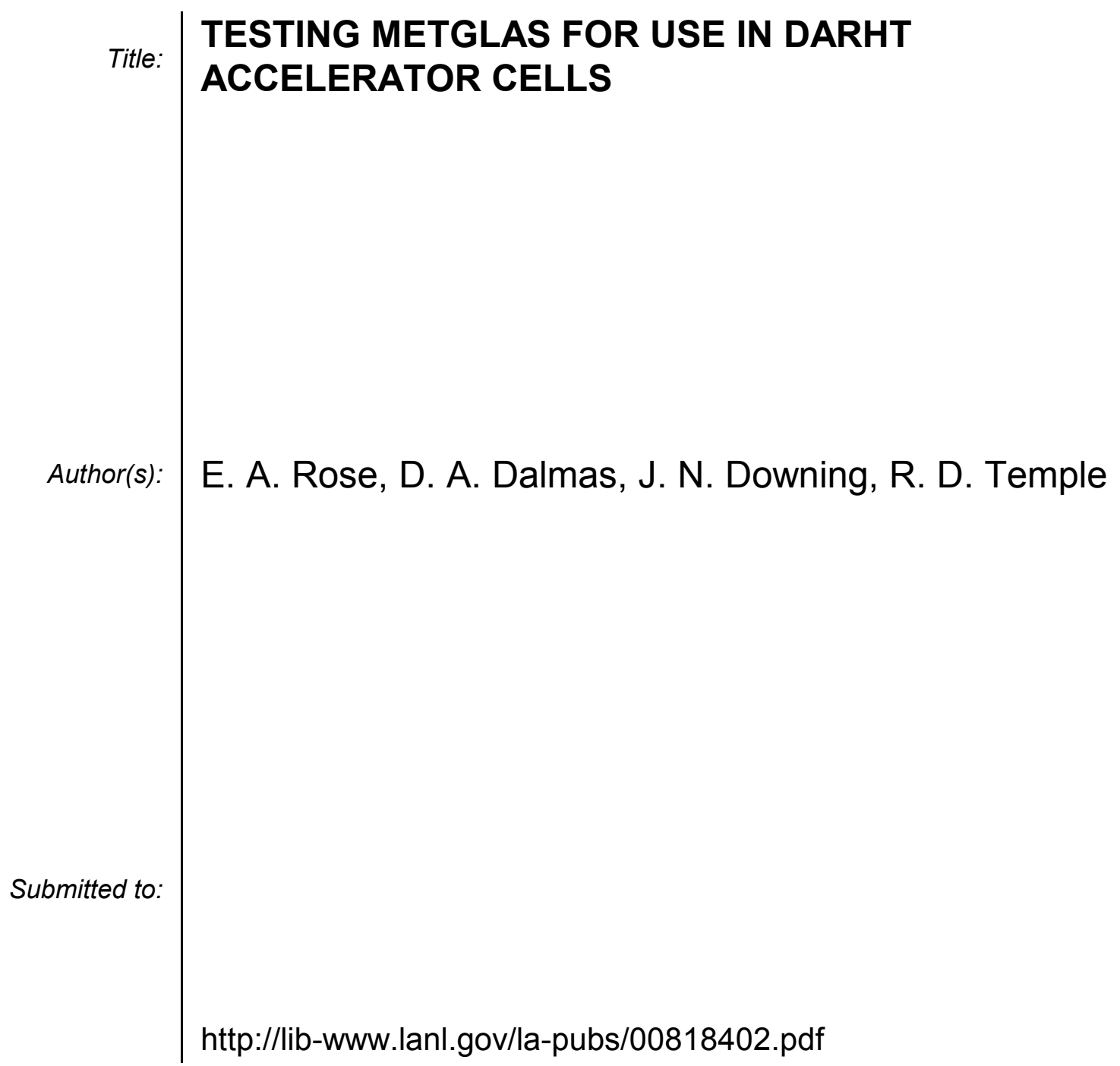

Los Alamos National Laboratory, an affirmative action/equal opportunity employer, is operated by the University of California for the U.S. Department of Energy under contract W-7405-ENG-36. By acceptance of this article, the publisher recognizes that the U.S. Government retains a nonexclusive, royaltyfree license to publish or reproduce the published form of this contribution, or to allow others to do so, for U.S. Government purposes. Los Alamos National Laboratory requests that the publisher identify this article as work performed under the auspices of the U.S. Department of Energy. Los Alamos National Laboratory strongly supports academic freedom and a researcher's right to publish; as an institution, however, the Laboratory does not endorse the viewpoint of a publication or guarantee its technical correctness. 


\title{
TESTING METGLAS FOR USE IN DARHT ACCELERATOR CELLS
}

\author{
E. A. Rose, D. A. Dalmas, J. N. Downing, R. D. Temple \\ Los Alamos National Laboratory, P.O.Box 1663, Mail Stop P-939 \\ Los Alamos, NM 87545, USA
}

\section{Abstract}

The Dual Axis Radiographic Hydrotest Facility [DARHT] at Los Alamos will use two induction linacs to produce high-energy electron beams. The electron beams will be used to generate $\mathrm{x}$-rays from bremsstrahlung targets. The x-rays will be used to produce radiographs. The first accelerator is operational now, producing a 60nanosecond electron beam. The second accelerator is under construction. It will produce a 2-microsecond electron beam.

The 78 induction cells of the second axis accelerator require a total Metglas capacity of approximately 40 volt seconds of flux. Four Metglas cores are used in each of the 5-foot diameter accelerator cells. Each Metglas core weighs approximately 3000 pounds.

This paper presents the measurement techniques and results of the Metglas tests. Routine automated analysis and archival of the pulse data provided hysteresis curves, energy loss curves and total flux swing in the operating regime. Results of the tests were used to help the manufacturer improve quality control and increase the average flux swing of the cores. Results of the tests were used to match Metglas cores and to assemble accelerator cells with equal volt-second ratings.

\section{INTRODUCTION}

The DARHT project involves a collaboration between three national laboratories - Lawrence Berkeley National Laboratory, Lawrence Livermore National Laboratory and Los Alamos National Laboratory. While the facility is sited at Los Alamos, the majority of the equipment design and production is performed at the other two laboratories.

The accelerator cells were designed by personnel at Lawrence Berkeley National Laboratory [1]. They chose the specific magnetic material used in the accelerator cells, and they developed a test procedure to ensure that the magnetic material met the requirements of the accelerator. The material chosen for the accelerator cells is Metglas 2605SC, manufactured by Honeywell in Conway, South Carolina.

The accelerator cells are required to deliver $195 \mathrm{kV}$ in a pulse that has a flattop lasting 2.02 microseconds. The volt-second requirement for the Metglas contained in each accelerator cell is $480 \mathrm{mV}$-sec. [For comparison, a linear ramp of $300 \mathrm{~ns}$ from $0 \mathrm{kV}$ to $195 \mathrm{kV}$, followed by a flattop of $2020 \mathrm{~ns}$ at $195 \mathrm{kV}$, would require $423 \mathrm{mV}$-sec.]
Personnel from Lawrence Berkeley National Laboratory built and shipped to us the measurement and test apparatus, including a LabVIEW program for data acquisition and analysis. There were three sets of test apparatus - one each at Lawrence Berkeley National Laboratory, Los Alamos National Laboratory, and the Honeywell fabrication plant in South Carolina. The objective was to test the material, measure the flux and mix and match the magnetic cores to achieve a constant volt-second value in each accelerator cell that met requirements.

\section{TEST CONDITIONS}

The core tester consists of a high voltage power supply connected to $1.2 \mu \mathrm{F}$ of capacitance with a Ross relay used as a drop switch. The capacitors are charged to a nominal $25 \mathrm{kV}$ by the power supply, then discharged through a wire loop, passing through the center of the Metglas core. A Pearson current monitor [10 amperes per volt] measures the current through the wire loop. The current measurement and core dimensions give $\mathrm{H}$ in amperes per meter. The current waveform is captured by a Tektronix TDS 540D digitizing oscilloscope.

A second wire loop passes through the center of the Metglas core, connected to a Tektronix P6015 1,000:1 high voltage probe. The voltage waveform is also digitized. The time-integrated voltage measurement gives the magnetic flux in volt-seconds [webers]. Magnetic flux and core dimensions give magnetic induction $\mathrm{B}$ in tesla.

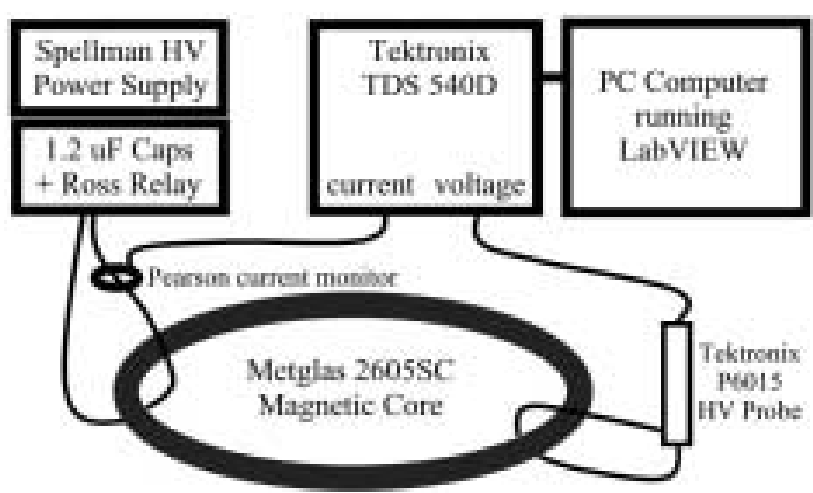

Figure 1. Experimental configuration for testing Metglas cores.

A LabVIEW program reads the waveforms into a personal computer. The user provides the program with 
core parameters and identifying information. Data analysis, display and storage are performed by the LabVIEW program. In particular, the program uses the core dimensions and integrated voltage to determine flux as a function of magnetic field strength $\mathrm{H}$.

The flux swing between $-600 \mathrm{~A} / \mathrm{m}$ and $+600 \mathrm{~A} / \mathrm{m}$ is determined and displayed by the program. Each accelerator cell will contain four cores that add up to 480 $\mathrm{mV}$-sec, using this technique.

Data can be recalled into the program for viewing and analysis at a later time.

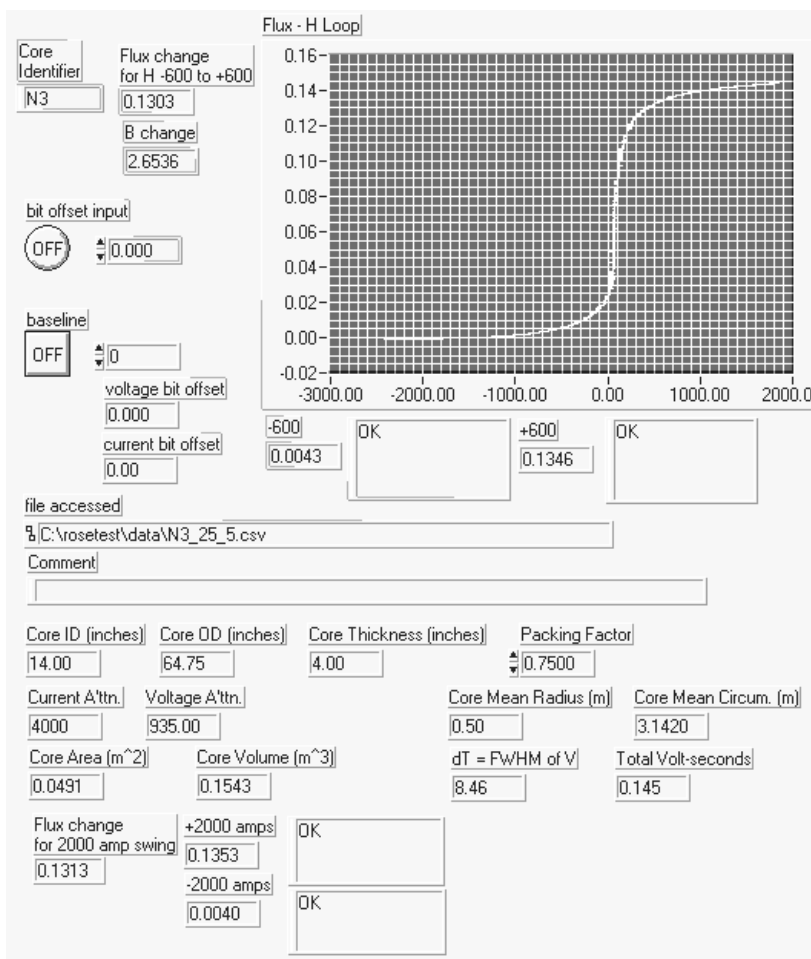

Figure2. Data analysis screen in LabVIEW. This core, N3 is measured at $130 \mathrm{mV}$-sec.

\section{FLUX MEASUREMENTS}

We received cores in batches of 12 . We measured 84 cores and discovered that our average accelerator cell would only contain $453 \mathrm{mV}$-sec, short of our required 480 $\mathrm{mV}$-sec and far short of our goal of $500 \mathrm{mV}$-sec.

Figure 3 shows the results of our tests. The histogram labels refer to the top value of the bin. For example, the label 92 represents cores that fall within the range 87 to $92 \mathrm{mV}$-sec. There are two populations of core measurements, because there are two different sizes of Metglas cores, with the smaller cores having $77 \%$ of the area of the larger cores. One small core and three large cores are used in each accelerator cell.

The average value of the small cores was $91 \mathrm{mV}$-sec, and the average value of the large cores was $119 \mathrm{mV}$-sec. The 84 cores represented half the number of cores necessary to build 40 cells. To achieve accelerator cells with $480 \mathrm{mV}$-sec, the new small cores would need to have
$104 \mathrm{mV}$-sec and the new large cores would need to have $134 \mathrm{mV}$-sec. This is an increase of $12 \%$.

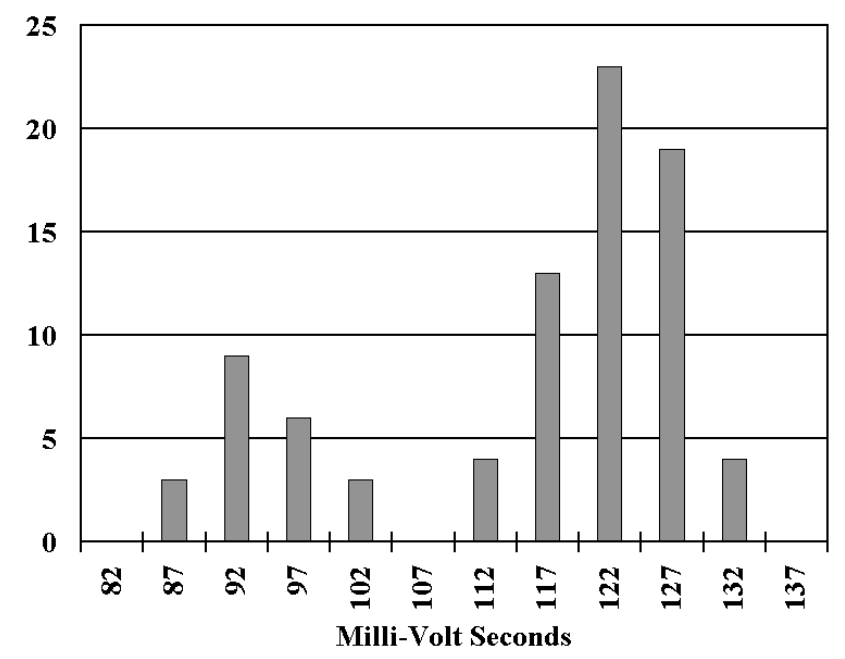

Figure 3. Results from tests of 84 Metglas cores.

Honeywell worked with their equipment and produced new Metglas cores that had higher flux swings. We received 92 of those new cores and measured them. The average flux had increased to $103 \mathrm{mV}$-sec for the small cores and $135 \mathrm{mV}$-sec for the large cores.

We were able to "mix and match" the new and old cores to get 40 sets of cores that totaled $480 \mathrm{mV}$-sec.

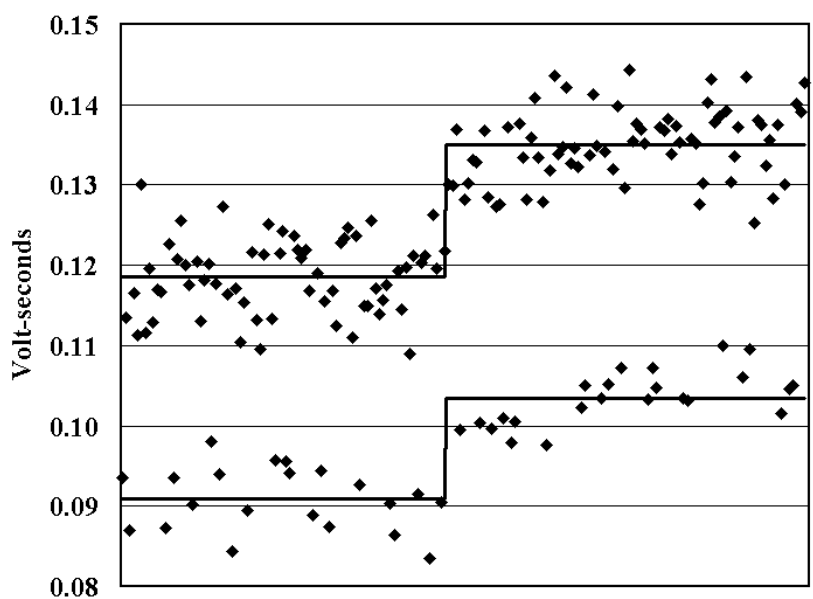

Figure 4. Metglas quality improves to meet requirements.

The improvement in Metglas quality is evident in Figure 4. The initial delivery of 84 cores is shown on the left, the population with the lower flux value represents the small cores. The later delivery of 92 cores is shown on the right. The dark line marks the average value of measured flux swing. It takes a marked jump upward.

\section{CONCLUSION}

Testing of 84 Metglas 2605SC cores at Los Alamos National Laboratory indicated that there were problems 
that would prevent us from producing 40 accelerator cells, each containing $480 \mathrm{mV}$-sec of magnetic material. Honeywell responded to our test results, worked with their equipment and produced higher quality material. Testing continued at Los Alamos, and the results were reported back to Honeywell. Honeywell produced enough higher quality material to offset our original problem. Mixing and matching cores from the original batch with the later batch gave 40 sets of cores that summed to $480 \mathrm{mV}$-sec. We are in the process of building the accelerator cells with these Metglas cores.

\section{ACKNOWLEDGEMENT}

This work was performed under the auspices of the U.S. Department of Energy under contract W-7405-ENG-36.

\section{REFERENCES}

[1] W. L. Waldron and L. L. Reginato, "Design and performance of the DARHT second axis induction cells and drivers," in $24^{\text {th }}$ International Power Modulator Symposium, 2000, p. 179. 